\title{
The Role of Compensatory Adaptations and Individual Variability in Exercise Prescription
}

\author{
Clemens Drenowatz \\ Department of Exercise Science, University of South Carolina, Columbia, SC 29208, USA; \\ drenowat@mailbox.sc.edu; Tel.: +1-803-777-9863 \\ Academic Editor: Laura Stefani \\ Received: 8 April 2016; Accepted: 6 May 2016; Published: 11 May 2016
}

\begin{abstract}
Physical inactivity is a major risk factor for public health. Due to the decline in physical demands of daily living exercise becomes an increasingly important contributor to an active lifestyle. The evidence on health benefits of exercise, particularly regarding weight loss, however, remains equivocal. In addition to lack of adherence to an exercise program, participants display behavioral and physiological adaptations that potentially mitigate exercise-induced health benefits. Specifically, a reduction in non-exercise physical activity (PA) and/or an increase in energy intake along with metabolic adaptations have been suggested to affect exercise-induced health benefits. There is also a large inter-individual variability, which makes some participants more receptive to exercise-induced weight loss than others. Even in the absence of weight loss exercise, however, provides various health benefits such as an increase in cardiorespiratory fitness, beneficial changes in blood lipids and blood pressure. In fact, some of these benefits have been more pronounced in participants who did not experience weight loss. In order to enhance the understanding of the role of exercise in health promotion a better understanding of compensatory adaptations is needed along with an identification of characteristics that contribute to inter-individual variability in response to exercise interventions.
\end{abstract}

Keywords: energy balance; weight loss; intervention; non-exercise physical activity; energy intake; behavioral compensation; metabolic compensation

\section{Introduction}

The benefits of regular physical activity (PA) have been well documented. Specifically, physical activity has been associated with a risk-reduction for cardiovascular disease (CVD), type II diabetes, overweight and obesity, several types of cancer and psychological well-being [1]. Accordingly, physical inactivity has been shown to reduce lifetime free of long-standing illness by eight years [2]. Nevertheless, in most countries of the world less than half of the adult population engages in recommended levels of PA [3]. Based on objective PA measures, the average U.S. adult accumulates only 6 to 10 min of moderate-to-vigorous PA per day, and less than $5 \%$ meet current PA recommendations [4]. Given these low rates of PA the World Health Organization estimates that 3.3 million deaths can be attributed to physical inactivity [5], making it the fourth leading risk factor for public health [6].

Low PA levels can in part be attributed to the lack of physical demands in our daily lives $[7,8]$. Exercise, which represents purposeful, planned and structured PA [9], therefore, has become increasingly important to ensure sufficient PA in order to maintain or enhance people's health and well-being. Research examining the beneficial effects of exercise on various health outcomes, however, has produced equivocal results. Particularly, the role of exercise in weight management remains debated as weight loss in response to exercise is often less than what would be expected [10-13]. In addition to an insufficient dose of exercise and lack of adherence to the program, participants may display physiological and behavioral compensatory adaptations that could influence exercise-induced 
health benefits [13]. Specifically, alterations in energy intake, non-exercise or habitual PA along with metabolic adaptations such as a decline in resting energy expenditure have been proposed to mitigate or even reverse exercise-induced weight loss [12-14]. Such compensatory adaptations, however, have been shown to vary by exercise intervention (i.e., exercise mode, intensity, duration) [15]. In addition, personal characteristics, including sex, age and body weight have been shown to contribute to the variability in the magnitude, type and direction of compensatory adaptations, resulting in inter-individual differences in health benefits obtained by engagement in exercise $[12,16,17]$. The focus on mean outcomes in response to exercise interventions, therefore, may provide misleading results. In fact, mean results potentially mask important trends at the individual level that could provide crucial information for the role of exercise and PA in health promotion $[18,19]$. Therefore, a better understanding of key characteristics that affect compensatory adaptations in response to exercise is needed to maximize the health benefits on an individual level. The large inter-individual variability in response to exercise further emphasizes the need for a more personalized exercise prescription to ensure optimal health benefits for each individual.

This narrative review provides an overview of major compensatory adaptations commonly experienced in response to exercise-based interventions with a particular focus on inter-individual variability in behavioral adjustments in response to exercise. Due to the attention in the popular media, a major emphasis is put on the role of exercise in weight management. Additional exercise-induced health benefits beyond the role in weight management, however, are addressed as well as this emphasizes the value of exercise in health promotion.

\section{Compensatory Adaptations in Response to Exercise Interventions}

Exercise has been shown to affect muscular and cellular metabolism, substrate oxidation, blood flow, and the secretion of hormones and neurotransmitters [20]. Given the complexity of acute and chronic exercise-induced changes in the human body it should not be surprising that there is the potential for exercise-induced physiological and behavioral adaptations that mitigate the effect of exercise on various health outcomes beyond a lack in adherence to the exercise program. The presence of compensatory adjustments in response to exercise has been shown over 35 years ago [21]. Particularly, behavioral adjustments in non-exercise PA and energy intake have been considered key contributors to the limited success in exercise-based weight-loss interventions (Figure 1) but there is also evidence for inter-individual differences in metabolic adaptations. In order to strengthen the efficacy of exercise in weight management it is crucial to enhance the understanding of key characteristics contributing to compensatory adaptations that go beyond adherence to the exercise program.

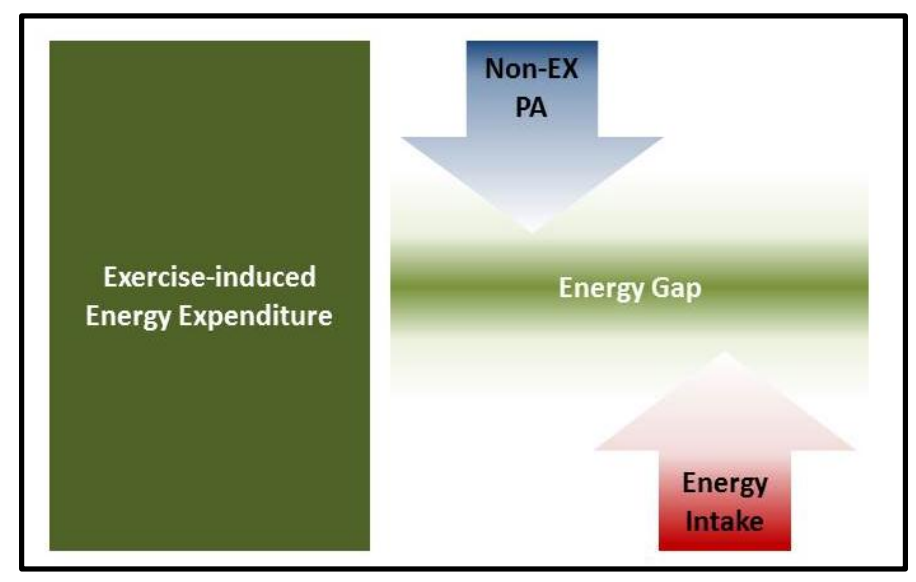

Figure 1. Behavioral compensatory adaptations in response to exercise that attenuate an exercise-induced energy gap. 
Given that a structured exercise program generally lasts for a relatively short period of time the effect of exercise on habitual PA or non-exercise PA could have a profound impact on exercise-induced changes in total daily energy expenditure (TDEE). Empirical evidence on the association between exercise and non-exercise PA (i.e., all activities other than volitional exercise, such as activities of daily living, fidgeting and muscle contraction for postural maintenance [12]), however, has been inconsistent. A recent review also indicates that duration of the exercise intervention may be a critical component regarding compensatory adaptations [15]. Specifically, shorter interventions lasting up to 3 months have been shown to induce a decline in non-exercise PA. The decline in non-exercise PA was generally less pronounced in interventions lasting longer than 6 months. This has, at least partially, been attributed to an increase in exercise tolerance and fitness as a result of prolonged exercise engagement [22]. Accordingly, lower fitness levels have been associated with a greater decline in non-exercise PA at the onset of an exercise program [23]. The importance of fitness and exercise tolerance was further pointed out by Schutz et al. who showed a greater reduction in non-exercise PA in response to a higher exercise volume [24]. Nevertheless, research on the effect of exercise intensity and duration on non-exercise PA has been limited and inconsistent [12,24,25]. In addition, exercise type may affect compensatory adaptations differently. The majority of exercise interventions, however, relied on aerobic exercise, which, at least partially, could be attributed to the higher energy expenditure of aerobic exercise compared to resistance exercise [26]. Limited data, nevertheless, indicates that resistance exercise may be associated with an increase in non-exercise PA [27,28], which could have important long-term implications for weight management.

Besides alterations in non-exercise PA, adjustments in energy intake can affect exercise-induced weight change. Given that energy intake is ultimately determined by a behavioral choice for food consumption it may actually be the largest source of compensatory adaptations. Various reviews have examined the association between exercise and energy intake and these should be consulted for detailed information [29-31]. In general, there appears to be a partial compensation in energy intake, particularly in more active and lean participants while compensatory changes in energy intake appear to be less pronounced in overweight/obese [15]. There is also a potential sex effect as women have been shown to be more likely to display compensatory changes in energy intake compared to men [32,33]. Findings by Church et al. further indicated a potential minimal threshold in exercise or energy expenditure that needs to be reached before compensatory alterations in energy intake may occur [34]. An increase in energy intake appears to be predominantly driven by a higher carbohydrate intake while findings regarding changes in fat and protein intake in response to exercise were less consistent [15]. The increase in carbohydrate intake seems to be more pronounced with higher exercise intensities, which may be attributed to the need to replenish muscle glycogen stores [35]. In fact, Pannacciulli et al. argue that the restoration of carbohydrates, rather than compensating for total energy expenditure, drives energy intake following exercise [36].

Even though energy intake is ultimately the result of eating behavior (i.e., consumption of foods and beverages), it is influenced by environmental and genetic constraints along with biological aspects that control energy intake [22]. Appetite control has been shown to be regulated by an interaction of adipose tissue with peripheral signals from intestinal peptides (i.e., insulin, ghrelin, GLP-1, CCK, PYY amylin, oxyntomodulin) [37]. Exercise has also been associated with changes in peptides affecting appetite (i.e., stimulation of energy intake) and satiety (i.e., cessation of meal consumption), as well as gastric emptying [19,31]. Accordingly, ratings of appetite and implicit wanting for foods, particularly for sweet and high-fat foods have been shown to increase in response to exercise interventions $[38,39]$. Further, changes in food cravings and/or mood following exercise have been associated with alterations energy intake $[40,41]$. Conclusive evidence on the effect of exercise on appetite and hunger as well as energy or macronutrient intake, however, remains limited. The lack of evidence has also been attributed to a lack of adequately powered trials that follow participants over a longer period of time and have an objective assessment of energy intake [29]. 
In addition to physiologic adaptations affecting energy intake there is evidence for metabolic adaptations that affect the expected increase in TDEE [13,14,42,43]. Particularly, a negative energy balance has been associated with a reduction in energy expenditure for growth, somatic repair, as well as suppressed reproductive activity and lactation [14]. Accordingly, resting metabolic rate (RMR) has been shown to decline in response to an exercise intervention to a greater extent than what could be attributed to changes in body weight or body composition [44,45]. On the other hand, there is evidence for an elevated RMR following an exercise bout, also known as excess post-exercise oxygen consumption (EPOC) [46]. As EPOC has been shown to stay elevated for up to $48 \mathrm{~h}$ following an exercise bout it could be argued that regular engagement in exercise may offset the declines observed with a negative energy balance [46,47]. This is in accordance with recent studies that showed a relatively stable RMR throughout an exercise intervention [38,48]. As has been addressed regarding the association between exercise and non-exercise PA there remains limited research on potential differences in response to various exercise types. In addition to the characteristics of the exercise intervention, participant characteristics such as sex and age need to be considered as well. Older adults and women have generally shown a greater likelihood for compensatory adaptations to an exercise program $[12,15,22,49]$. Even in relatively homogeneous samples there is, however, large inter-individual variability regarding various health outcomes in the response to exercise. The large inter-individual variability in various adaptations in response to exercise may also explain some of the inconsistent findings shown previously. Particularly the role of exercise in weight loss remains controversial as some participants may be quite susceptible to exercise-induced weight loss, while others may experience a less than expected weight loss or even weight gain [12]. In order to enhance the understanding of the role of exercise in weight management and general health, a stronger emphasis on these individual differences, therefore, is warranted.

Table 1. Range of weight change in response to supervised exercise interventions.

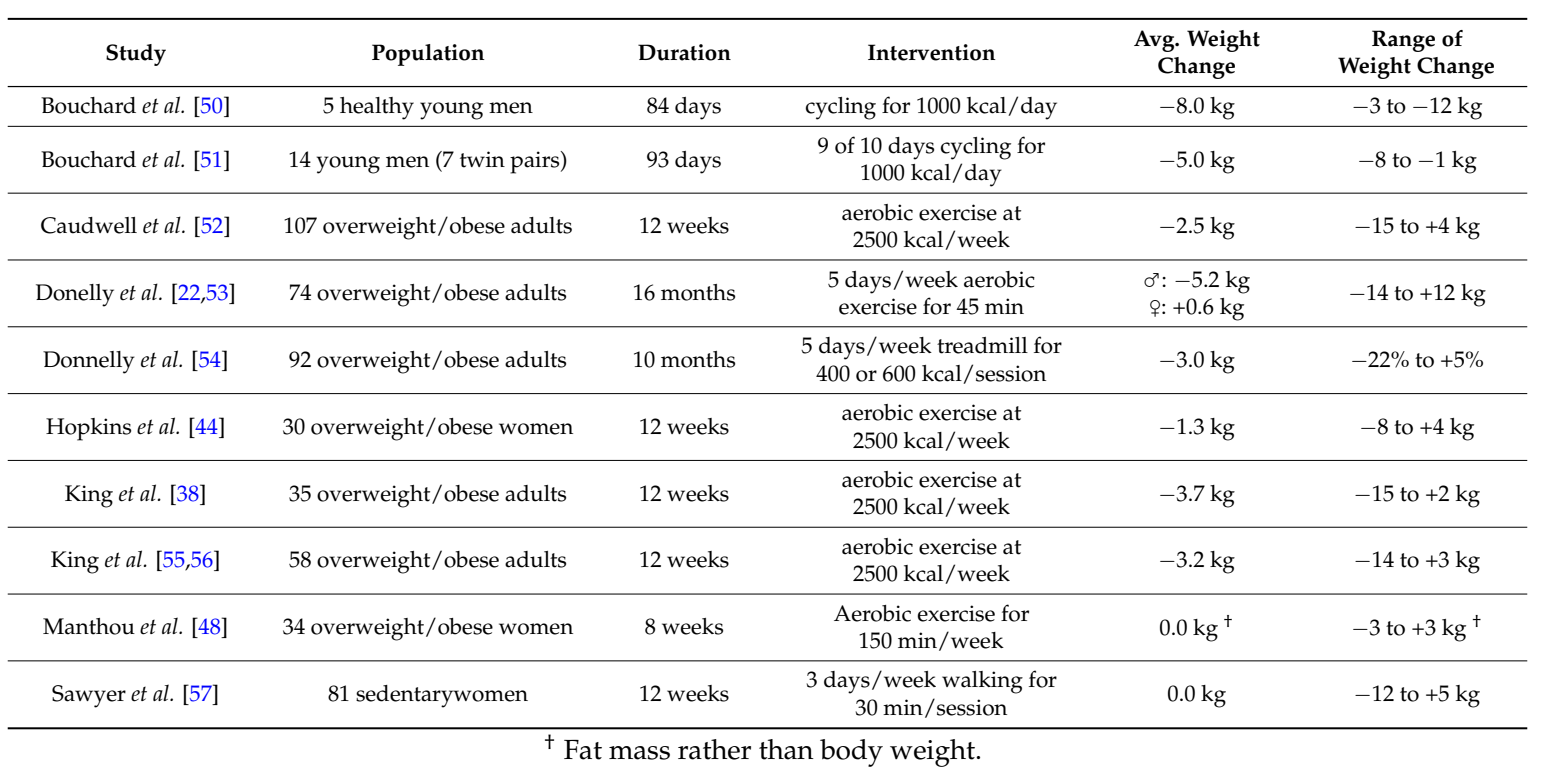

\section{Individual Variability in Compensatory Adaptations in Response to Exercise}

Inter-individual variability in the direction and magnitude of weight change in response to supervised exercise-based interventions has been well documented (Table 1). Even in a highly controlled setting of an isolated experimental station over an 84-day period exercise induced weight loss ranged between 3 and $12 \mathrm{~kg}$ [50]. More recent studies showed that certain participants even gain weight in response to supervised exercise interventions [44,57]. Accordingly, changes in fat mass and fat free mass have been shown to vary considerably [38,44]. King et al. showed roughly a 50:50 split between so-called "responders" (i.e., participants who achieve expected weight loss) and 
"non-responders" (i.e., participants who experience only a small amount of weight loss or weight gain) [38]. Other studies indicate that a majority of participants displays some form of compensatory adaptation with a ratio of responders to non-responders of 1:2 [48,57]. Even though there is, most likely, considerable inter-individual variability in metabolic adaptations in response to exercise $[44,50]$, success in weight loss interventions has been largely attributed to behavioral compensation such as a decline in non-exercise PA and/or an increase in energy intake [22,38,48]; in addition to an obvious association with adherence to the exercise protocol. In fact, it has been argued that the individual variability in weight loss can be entirely attributed to the variability in non-exercise PA [48,58]. Accordingly, various studies have shown that individual variability in weight change in response to exercise is not predicted by changes in energy intake [48,52-54]. Even in the absence of weight change there has been a large inter-individual variability in non-exercise PA, which may also affect other exercise induced health benefits (Figure 2).

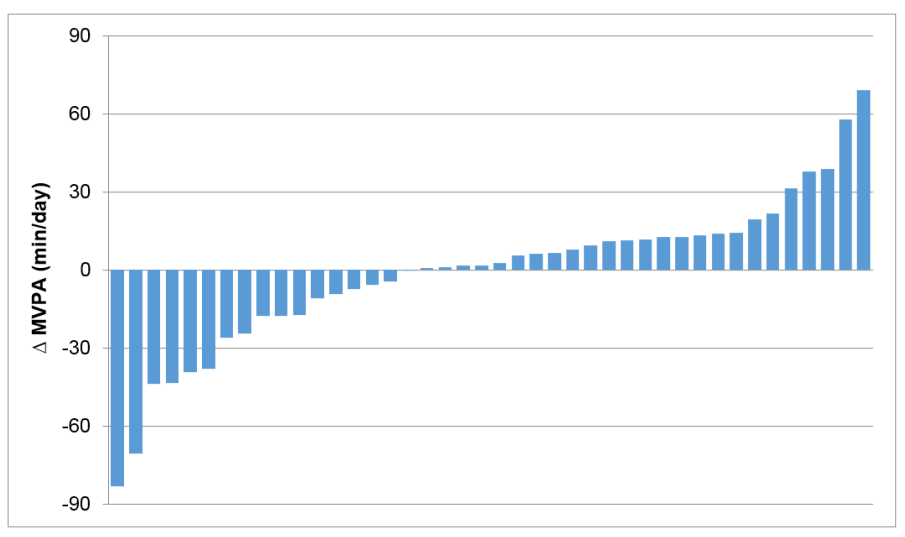

Figure 2. Individual variability in non-exercise physical activity (PA) in response to a 3-month exercise intervention under weight stable conditions. $\Delta$ moderate-to-vigorous PA (MVPA) difference in non-exercise MVPA, between baseline and 3-month follow-up.

Nevertheless, variability in energy intake still warrants consideration when exploring individual variability in various health outcomes in response to exercise. This may be of particular importance as individual differences in the hedonic evaluation of food and altered food preferences in response to exercise have been suggested to be stable characteristics [19]. Various studies also showed significant increases in hunger and energy intake in participants who experienced less than expected weight loss $[12,19,38]$. In addition to physiological adaptations that stimulate food intake there may also be psychological aspects that contribute to an increase in energy intake. Some individuals may feel a greater freedom to consume more food in subsequent meals or potentially choose to "reward" themselves with a snack following the completion of an exercise session. Taken together, the inter-individual variability in compensatory eating behavior following exercise should not be ignored when evaluating the lack of exercise-induced weight loss in certain people [12,59]. More research, however, is needed that explores physiological and psychological traits of responders and non-responders regarding exercise-induced weight loss. The ability to identify participants who will most likely experience a minimal weight loss in response to exercise would allow for a more targeted approach, which may include dietary counseling or dietary restriction [12].

While weight loss is a commonly used motivation for exercise engagement it should be pointed out that exercise provides valuable health benefits in the absence of weight loss as well. A change in fat mass and fat free mass along with a change in the distribution of fat tissue may not be evident by simply considering change in body weight. Such changes, however, can have more pronounced health benefits than weight loss per se [60,61]. In addition, individuals who may not achieve a significant weight loss can experience beneficial changes in blood pressure, insulin sensitivity, blood lipid levels and cardiorespiratory fitness $[19,56,62]$. As has been shown for exercise-induced weight change there 
is a large inter-individual variability in exercise-induced change in VO2peak $[16,63,64]$ and other CVD risk factors $[16,17,65]$. A highly controlled 20-week exercise intervention showed that only $11 \%$ of the variability in VO2peak could be explained by age, sex, race and baseline VO2peak [16], emphasizing the need to further explore additional traits that contribute to variability in response to exercise. It should also be pointed out that there appears to be no difference in the increase in VO2peak between participants classified as responders or non-responders based on weight change [48]. Further, participants who displayed a less than expected weight loss experienced a more pronounced drop in blood pressure compared to participants achieving or exceeding the expected weight loss [56]. Given the complexity of exercise-induced changes in the human body it is likely that most people display some form of compensatory adjustments but these adaptations will vary considerably across individuals. Some participants may show a decline in non-exercise PA in response to exercise while others may increase their energy intake and another group may display metabolic adaptations. Due to the variability in exercise-induced adaptations it is, however, unlikely that anybody is entirely immune to exercise and participation in regular PA or exercise will induce some health benefits for everyone [66]. Future research, therefore, should focus on the identification of specific characteristics that contribute to compensatory adaptations that make certain individuals more or less receptive to exercise induced changes in specific health outcomes. A better understanding of the inter-individual variability will also help with a more tailored exercise prescription, which could enhance exercise-induced health benefits.

\section{Summary and Conclusions}

PA and exercise are considered important aspects of a healthy lifestyle. Nevertheless, a majority of adults remains insufficiently active. This may in part be due to a persistent skepticism on the health benefits of exercise, particularly regarding weight loss and weight management. As has been shown with this review, there is a large inter-individual variability in response to exercise and some individuals may not experience weight loss or may even gain weight in response to an exercise intervention due to compensatory adaptations such as an increase in energy intake and/or a decline in non-exercise PA. This subpopulation is often over-emphasized in the media and contributes to a public perception that exercise is of limited use in weight loss or weight management [12,67]. In addition, mean weight loss on the group level is commonly less than what would have been expected from the exercise intervention. Reliance on group means, however, not only fails to address the inter-individual variability in response to exercise; it potentially leads to misinterpretation of the role of exercise on the individual level. Dilnot actually referred to this common weakness in science as "tyranny of the average" [68]. Part of the variability in exercise-induced health benefits can be attributed to differences in adherence to the exercise program along with differences in duration, type and volume of the exercise intervention. In addition, differences in age, sex and weight status of the study population may have contributed to the variability in exercise-induced changes. Nevertheless, there remains considerable inter-individual variability even under highly controlled circumstances in relatively homogenous groups. Thus a fixed dose of exercise is unlikely to provide similar benefits to all individuals. Everybody, however, is expected to experience exercise-induced health benefits even though specifics may vary.

The phenomenon of inter-individual variability has actually been well established in the clinical environment with drug effectiveness generally ranging between $25 \%$ and $60 \%$ [69]. Therefore, it should not be surprising that the effectiveness of exercise on a specific health outcome, such as body weight or body composition, varies considerably across individuals. Contrary to many drugs, exercise, however, induces a variety of positive "side-effects" even in the absence of a significant impact on weight change (i.e., beneficial effects on metabolic profile and cardiorespiratory fitness). Currently, there is no indication that certain people are universally resistant to exercise induced health benefits. Nevertheless, an individually tailored approach in exercise prescription could help to optimize exercise-induced health benefits at the individual level. Further, the evaluation of exercise-based intervention programs should go beyond the examination of mean values. Rather, future research should focus on variability in exercise induced changes, which could help with the identification of individuals that are likely 
to display compensatory adaptations that potentially mitigate the effect of exercise on the outcome of interest. A possible approach may be to look for specific personality characteristics along with biomarkers or genetic traits that differentiate compensators from non-compensators in different settings. Such information could be subsequently used for the development of screening tools to identify participants who are more or less receptive to specific exercise interventions prior to or at least early in the intervention process.

Key compensatory adaptations include a reduction in non-exercise PA and/or an increase in energy intake along with metabolic adaptations. A better understanding of specific characteristics that may trigger compensatory adaptations would allow for an incorporation of additional strategies into the intervention program to improve the efficacy of exercise in clinical practice. Kozey-Keadle et al., for example, showed that compensation in non-exercise PA can be mitigated when sedentary behavior and habitual PA are specifically addressed on top of an exercise intervention [70]. For some participants the simple awareness of the potential for compensatory adaptations may be sufficient to avoid behavioral changes that could offset exercise-induced health benefits, while others may need a more structured and formal support. Even a highly individualized and closely monitored plan, however, does not guarantee the intended outcome. Thus participants need to be made aware that exercise engagement provides various health benefits beyond a change in body weight that may not always be on immediate display or on their minds. Emphasizing the wide variety of health benefits including psychological well-being along with an individualized exercise program, therefore, may be an important aspect in the promotion of sustained engagement in exercise or regular PA, which could have a huge impact on public health and the healthcare system.

Conflicts of Interest: The author declares no conflict of interest.

\section{Abbreviations}

The following abbreviations are used in this manuscript:

$\begin{array}{ll}\text { CVD } & \text { Cardio-Vascular Disease } \\ \text { EPOC } & \text { Excess Post-exercise Oxygen Consumption } \\ \text { PA } & \text { Physical Activity } \\ \text { RMR } & \text { Resting Metabolic Rate } \\ \text { TDEE } & \text { Total Daily Energy Expenditure }\end{array}$

\section{References}

1. O’Donovan, G.; Blazevich, A.J.; Boreham, C.; Cooper, A.R.; Crank, H.; Ekelund, U.; Fox, K.R.; Gately, P.; Giles-Corti, B.; Gill, J.M.; et al. The ABC of physical activity for health: A consensus statement from the British Association of Sport and Exercise Sciences. J. Sports Sci. 2010, 28, 573-591. [CrossRef] [PubMed]

2. Brønnum-Hansen, H.; Juel, K.; Davidsen, M.; Sørensen, J. Impact of selected risk factors on expected lifetime without long-standing, limiting illness in Denmark. Prev. Med. 2007, 45, 49-53. [CrossRef] [PubMed]

3. World Health Organization. Global Health Observatory Data Repository, 2011. Available online: http:/ /apps.who.int/gho/data/node.main.A893?lang=en (accessed on 30 March 2016).

4. Troiano, R.P.; Berrigan, D.; Dodd, K.W.; Masse, L.C.; Tilert, T.; McDowell, M. Physical activity in the United States measured by accelerometer. Med. Sci. Sports Exerc. 2008, 40, 181-188. [CrossRef] [PubMed]

5. World Health Organisation. Global Health Risks; WHO Press: Geneva, Switzerland, 2009.

6. World Health Organization. Global Recommendations on Physical Activity for Health; WHO Press: Geneva, Switzerland, 2010.

7. Church, T.S.; Thomas, D.M.; Tudor-Locke, C.; Katzmarzyk, P.T.; Earnest, C.P.; Rodarte, R.Q.; Martin, C.K.; Blair, S.N.; Bouchard, C. Trends over 5 decades in U.S. occupation-related physical activity and their associations with obesity. PLoS ONE 2011, 6, e19657. [CrossRef] [PubMed]

8. Archer, E.; Shook, R.P.; Thomas, D.M.; Church, T.S.; Katzmarzyk, P.T.; Hébert, J.R.; McIver, K.L.; Hand, G.A.; Lavie, C.J.; Blair, S.N. 45-year trends in women's use of time and household management energy expenditure. PLoS ONE 2013, 8, e56620. [CrossRef] [PubMed] 
9. Caspersen, C.J.; Powell, K.E.; Christenson, G.M. Physical activity, exercise, and physical fitness: Definitions and distinctions for health-related research. Public Health Rep. 1985, 100, 126-131. [PubMed]

10. Miller, W.C.; Koceja, D.M.; Hamilton, E.J. A meta-analysis of the past 25 years of weight loss research using diet, exercise or diet plus exercise intervention. Int. J. Obes. Relat. Metab. Disord. 1997, 21, 941-947. [CrossRef] [PubMed]

11. Dhurandhar, E.J.; Kaiser, K.A.; Dawson, J.A.; Alcorn, A.S.; Keating, K.D.; Allison, D.B. Predicting adult weight change in the real world: A systematic review and meta-analysis accounting for compensatory changes in energy intake or expenditure. Int. J. Obes. (Lond.) 2014, 39, 1181-1187. [CrossRef] [PubMed]

12. Melanson, E.L.; Keadle, S.K.; Donnelly, J.E.; Braun, B.; King, N.A. Resistance to exercise-induced weight loss: Compensatory behavioral adaptations. Med. Sci. Sports Exerc. 2013, 45, 1600-1609. [CrossRef] [PubMed]

13. Thomas, D.M.; Bouchard, C.; Church, T.; Slentz, C.; Kraus, W.E.; Redman, L.M.; Martin, C.K.; Silva, A.M.; Vossen, M.; Westerterp, K.; et al. Why do individuals not lose more weight from an exercise intervention at a defined dose? An energy balance analysis. Obes. Rev. 2012, 13, 835-847. [CrossRef] [PubMed]

14. Pontzer, H.; Durazo-Arvizu, R.; Dugas, L.R.; Plange-Rhule, J.; Bovet, P.; Forrester, T.E.; Lambert, E.V.; Cooper, R.S.; Schoeller, D.A.; Luke, A. Constrained total energy expenditure and metabolic adaptation to physical activity in adult humans. Curr. Biol. 2016, 26, 410-417. [CrossRef] [PubMed]

15. Drenowatz, C. Reciprocal compensation to changes in dietary intake and energy expenditure within the concept of energy balance. Adv. Nutr. 2015, 6, 592-599. [CrossRef] [PubMed]

16. Bouchard, C.; Rankinen, T. Individual differences in response to regular physical activity. Med. Sci. Sports Exerc. 2001, 33, S446-S453. [CrossRef] [PubMed]

17. Bouchard, C.; Blair, S.N.; Church, T.S.; Earnest, C.P.; Hagberg, J.M.; Häkkinen, K.; Jenkins, N.T.; Karavirta, L.; Kraus, W.E.; Leon, A.S.; et al. Adverse metabolic response to regular exercise: Is it a rare or common occurrence? PLoS ONE 2012, 7, e37887. [CrossRef] [PubMed]

18. King, N.; Caudwell, P.; Hopkins, M.; Byrne, N.; Colley, R.; Hills, A.; Stubbs, J.; Blundell, J. Metabolic and behavioral compensatory responses to exercise interventions: Barriers to weight loss. Obesity 2007, 15, 1373-1383. [CrossRef] [PubMed]

19. King, N.A.; Horner, K.; Hills, A.P.; Byrne, N.M.; Wood, R.E.; Bryant, E.; Caudwell, P.; Finlayson, G.; Gibbons, C.; Hopkins, M.; et al. Exercise, appetite and weight management: Understanding the compensatory responses in eating behaviour and how they contribute to variability in exercise-induced weight loss. Br. J. Sports Med. 2012, 46, 315-322. [CrossRef] [PubMed]

20. Hawley, J.A.; Holloszy, J.O. Exercise: It's the real thing! Nutr. Rev. 2009, 67, 172-178. [CrossRef] [PubMed]

21. Epstein, L.H.; Wing, R.R. Aerobic exercise and weight. Addict. Behav. 1980, 5, 371-388. [CrossRef]

22. Donnelly, J.E.; Smith, B.K. Is exercise effective for weight loss with ad libitum diet? Energy balance, compensation, and gender differences. Exerc. Sport Sci. Rev. 2005, 33, 169-174. [CrossRef] [PubMed]

23. Colley, R.C.; Hills, A.P.; King, N.A.; Byrne, N.M. Exercise-induced energy expenditure: Implications for exercise prescription and obesity. Patient Educ. Couns. 2010, 79, 327-332. [CrossRef] [PubMed]

24. Schutz, Y.; Nguyen, D.M.; Byrne, N.M.; Hills, A.P. Effectiveness of three different walking prescription durations on total physical activity in normal- and over-weight women. Obes. Facts 2014, 7, $264-273$. [PubMed]

25. Li, J.; O'Connor, L.E.; Zhou, J.; Campbell, W.W. Exercise patterns, ingestive behaviors, and energy balance. Physiol. Behav. 2014, 134, 70-75. [CrossRef] [PubMed]

26. Strasser, B.; Schobersberger, W. Evidence for resistance training as a treatment therapy in obesity. J. Obes. 2011, 2011. [CrossRef] [PubMed]

27. Hunter, G.R.; Wetzstein, C.J.; Fields, D.A.; Brown, A.; Bamman, M.M. Resistance training increases total energy expenditure and free-living physical activity in older adults. J. Appl. Physiol. 2000, 89, 977-984. [PubMed]

28. Drenowatz, C.; Grieve, G.L.; DeMello, M.M. Change in energy expenditure and physical activity in response to aerobic and resistance exercise programs. Springerplus 2015, 4. [CrossRef] [PubMed]

29. Donnelly, J.E.; Herrmann, S.D.; Lambourne, K.; Szabo, A.N.; Honas, J.J.; Washburn, R.A. Does increased exercise or physical activity alter ad-libitum daily energy intake or macronutrient composition in healthy adults? A systematic review. PLoS ONE 2014, 9, e83498. [CrossRef] [PubMed] 
30. Blundell, J.E.; Caudwell, P.; Gibbons, C.; Hopkins, M.; Naslund, E.; King, N.; Finlayson, G. Role of resting metabolic rate and energy expenditure in hunger and appetite control: A new formulation. Dis. Model. Mech. 2012, 5, 608-613. [CrossRef] [PubMed]

31. Hopkins, M.; King, N.A.; Blundell, J.E. Acute and long-term effects of exercise on appetite control: Is there any benefit for weight control? Curr. Opin. Clin. Nutr. Metab. Care 2010, 13, 635-640. [CrossRef] [PubMed]

32. Stubbs, R.J.; Sepp, A.; Hughes, D.A.; Johnstone, A.M.; King, N.; Horgan, G.; Blundell, J.E. The effect of graded levels of exercise on energy intake and balance in free-living women. Int. J. Obes. Relat. Metab. Disord. 2002, 26, 866-869. [PubMed]

33. Stubbs, R.J.; Sepp, A.; Hughes, D.A.; Johnstone, A.M.; Horgan, G.W.; King, N.; Blundell, J. The effect of graded levels of exercise on energy intake and balance in free-living men, consuming their normal diet. Eur. J. Clin. Nutr. 2002, 56, 129-140. [CrossRef] [PubMed]

34. Church, T.S.; Martin, C.K.; Thompson, A.M.; Earnest, C.P.; Mikus, C.R.; Blair, S.N. Changes in weight, waist circumference and compensatory responses with different doses of exercise among sedentary, overweight postmenopausal women. PLoS ONE 2009, 4, e4515. [CrossRef] [PubMed]

35. Pomerleau, M.; Imbeault, P.; Parker, T.; Doucet, E. Effects of exercise intensity on food intake and appetite in women. Am. J. Clin. Nutr. 2004, 80, 1230-1236. [PubMed]

36. Pannacciulli, N.; Salbe, A.D.; Ortega, E.; Venti, C.A.; Bogardus, C.; Krakoff, J. The 24-h carbohydrate oxidation rate in a human respiratory chamber predicts ad libitum food intake. Am. J. Clin. Nutr. 2007, 86, 625-632. [PubMed]

37. Badman, M.K.; Flier, J.S. The gut and energy balance: Visceral allies in the obesity wars. Science 2005, 307, 1909-1914. [CrossRef] [PubMed]

38. King, N.A.; Hopkins, M.; Caudwell, P.; Stubbs, R.J.; Blundell, J.E. Individual variability following 12 weeks of supervised exercise: Identification and characterization of compensation for exercise-induced weight loss. Int. J. Obes. (Lond.) 2008, 32, 177-184. [CrossRef] [PubMed]

39. Finlayson, G.; Bryant, E.; Blundell, J.E.; King, N.A. Acute compensatory eating following exercise is associated with implicit hedonic wanting for food. Physiol. Behav. 2009, 97, 62-67. [CrossRef] [PubMed]

40. Taylor, A.H.; Oliver, A.J. Acute effects of brisk walking on urges to eat chocolate, affect, and responses to a stressor and chocolate cue. An experimental study. Appetite 2009, 52, 155-160. [CrossRef] [PubMed]

41. Schneider, K.L.; Spring, B.; Pagoto, S.L. Exercise and energy intake in overweight, sedentary individuals. Eat. Behav. 2009, 10, 29-35. [CrossRef] [PubMed]

42. Pontzer, H. Constrained total energy expenditure and the evolutionary biology of energy balance. Exerc. Sport Sci. Rev. 2015, 43, 110-116. [CrossRef] [PubMed]

43. Westerterp, K.R.; Meijer, G.A.; Janssen, E.M.; Saris, W.H.; Ten Hoor, F. Long-term effect of physical activity on energy balance and body composition. Br. J. Nutr. 1992, 68, 21-30. [CrossRef] [PubMed]

44. Hopkins, M.; Gibbons, C.; Caudwell, P.; Hellström, P.M.; Näslund, E.; King, N.A.; Finlayson, G.; Blundell, J.E. The adaptive metabolic response to exercise-induced weight loss influences both energy expenditure and energy intake. Eur. J. Clin. Nutr. 2014, 68, 581-586. [CrossRef] [PubMed]

45. Doucet, E.; Imbeault, P.; St-Pierre, S.; Alméras, N.; Mauriège, P.; Després, J.P.; Bouchard, C.; Tremblay, A. Greater than predicted decrease in energy expenditure during exercise after body weight loss in obese men. Clin. Sci. (Lond.) 2003, 105, 89-95. [CrossRef] [PubMed]

46. Speakman, J.R.; Selman, C. Physical activity and resting metabolic rate. Proc. Nutr. Soc. 2003, 62, $621-634$. [CrossRef] [PubMed]

47. Wilmore, J.H.; Stanforth, P.R.; Hudspeth, L.A.; Gagnon, J.; Daw, E.W.; Leon, A.S.; Rao, D.C.; Skinner, J.S.; Bouchard, C. Alterations in resting metabolic rate as a consequence of 20 wk of endurance training: The heritage family study. Am. J. Clin. Nutr. 1998, 68, 66-71. [PubMed]

48. Manthou, E.; Gill, J.M.; Wright, A.; Malkova, D. Behavioural compensatory adjustments to exercise training in overweight women. Med. Sci. Sports Exerc. 2010, 42, 1121-1128. [CrossRef] [PubMed]

49. Westerterp, K.R. Impacts of vigorous and non-vigorous activity on daily energy expenditure. Proc. Nutr. Soc. 2003, 62, 645-650. [CrossRef] [PubMed]

50. Bouchard, C.; Tremblay, A.; Nadeau, A.; Dussault, J.; Després, J.P.; Theriault, G.; Lupien, P.J.; Serresse, O.; Boulay, M.R.; Fournier, G. Long-term exercise training with constant energy intake. 1: Effect on body composition and selected metabolic variables. Int. J. Obes. 1990, 14, 57-73. [PubMed] 
51. Sawyer, B.J.; Bhammar, D.M.; Angadi, S.S.; Ryan, D.M.; Ryder, J.R.; Sussman, E.J.; Bertmann, F.M.; Gaesser, G.A. Predictors of fat mass changes in response to aerobic exercise training in women. J. Strength Cond. Res. 2015, 29, 297-304. [CrossRef] [PubMed]

52. Levine, J.A.; Eberhardt, N.L.; Jensen, M.D. Role of nonexercise activity thermogenesis in resistance to fat gain in humans. Science 1999, 283, 212-214. [CrossRef] [PubMed]

53. Caudwell, P.; Gibbons, C.; Hopkins, M.; King, N.; Finlayson, G.; Blundell, J. No sex difference in body fat in response to supervised and measured exercise. Med. Sci. Sports Exerc. 2013, 45, 351-358. [CrossRef] [PubMed]

54. Donnelly, J.E.; Hill, J.O.; Jacobsen, D.J.; Potteiger, J.; Sullivan, D.K.; Johnson, S.L.; Heelan, K.; Hise, M.; Fennessey, P.V.; Sonko, B.; et al. Effects of a 16-month randomized controlled exercise trial on body weight and composition in young, overweight men and women: The midwest exercise trial. Arch. Intern. Med. 2003, 163, 1343-1350. [CrossRef] [PubMed]

55. Donnelly, J.E.; Honas, J.J.; Smith, B.K.; Mayo, M.S.; Gibson, C.A.; Sullivan, D.K.; Lee, J.; Herrmann, S.D.; Lambourne, K.; Washburn, R.A. Aerobic exercise alone results in clinically significant weight loss for men and women: Midwest exercise trial 2. Obesity (Silver Spring) 2013, 21, E219-E228. [CrossRef] [PubMed]

56. Bouchard, C.; Tremblay, A.; Després, J.P.; Thériault, G.; Nadeau, A.; Lupien, P.J.; Moorjani, S.; Prudhomme, D.; Fournier, G. The response to exercise with constant energy intake in identical twins. Obes. Res. 1994, 2, 400-410. [CrossRef] [PubMed]

57. King, N.A.; Caudwell, P.P.; Hopkins, M.; Stubbs, J.R.; Naslund, E.; Blundell, J.E. Dual-process action of exercise on appetite control: Increase in orexigenic drive but improvement in meal-induced satiety. Am. J. Clin. Nutr. 2009, 90, 921-927. [CrossRef] [PubMed]

58. King, N.A.; Hopkins, M.; Caudwell, P.; Stubbs, R.J.; Blundell, J.E. Beneficial effects of exercise: Shifting the focus from body weight to other markers of health. Br. J. Sports Med. 2009, 43, 924-927. [CrossRef] [PubMed]

59. Hopkins, M.; Blundell, J.E.; King, N.A. Individual variability in compensatory eating following acute exercise in overweight and obese women. Br. J. Sports Med. 2014, 48, 1472-1476. [CrossRef] [PubMed]

60. Oliveros, E.; Somers, V.K.; Sochor, O.; Goel, K.; Lopez-Jimenez, F. The concept of normal weight obesity. Prog. Cardiovasc. Dis. 2014, 56, 426-433. [CrossRef] [PubMed]

61. Bastien, M.; Poirier, P.; Lemieux, I.; Després, J.P. Overview of epidemiology and contribution of obesity to cardiovascular disease. Prog. Cardiovasc. Dis. 2014, 56, 369-381. [CrossRef] [PubMed]

62. Fogelholm, M. Physical activity, fitness and fatness: Relations to mortality, morbidity and disease risk factors. A systematic review. Obes. Rev. 2010, 11, 202-221. [CrossRef] [PubMed]

63. Bouchard, C. Individual differences in the response to regular exercise. Int. J. Obes. Relat. Metab. Disord. 1995, 19, S5-S8. [PubMed]

64. Bouchard, C.; An, P.; Rice, T.; Skinner, J.S.; Wilmore, J.H.; Gagnon, J.; Pérusse, L.; Leon, A.S.; Rao, D.C. Familial aggregation of $\mathrm{VO}(2 \mathrm{max})$ response to exercise training: Results from the heritage family study. J. Appl. Physiol. 1999, 87, 1003-1008. [PubMed]

65. Leon, A.S.; Gaskill, S.E.; Rice, T.; Bergeron, J.; Gagnon, J.; Rao, D.C.; Skinner, J.S.; Wilmore, J.H.; Bouchard, C. Variability in the response of HDL cholesterol to exercise training in the HERITAGE family study. Int. J. Sports Med. 2002, 23, 1-9. [CrossRef] [PubMed]

66. Warburton, D.E.; Bredin, S.S. Reflections on physical activity and health: What should we recommend? Can. J. Cardiol. 2016, 32, 495-504. [CrossRef] [PubMed]

67. Blundell, J.E.; Gibbons, C.; Caudwell, P.; Finlayson, G.; Hopkins, M. Appetite control and energy balance: Impact of exercise. Obes. Rev. 2015, 16, 67-76. [CrossRef] [PubMed]

68. Dilnot, A. The Tiger that Isn't: Seeing through a World of Numbers; Profile Books: London, UK, 2008.

69. Wilkinson, G.R. Drug metabolism and variability among patients in drug response. N. Engl. J. Med. 2005, 352, 2211-2221. [CrossRef] [PubMed]

70. Kozey-Keadle, S.; Staudenmayer, J.; Libertine, A.; Mavilia, M.; Lyden, K.; Braun, B.; Freedson, P. Changes in sedentary time and physical activity in response to an exercise training and/or lifestyle intervention. J. Phys. Act. Health 2014, 11, 1324-1333. [CrossRef] [PubMed]

(C) 2016 by the author; licensee MDPI, Basel, Switzerland. This article is an open access article distributed under the terms and conditions of the Creative Commons Attribution (CC-BY) license (http://creativecommons.org/licenses/by/4.0/). 